\title{
CENTRIFUGAÇÃO DE ESPERMATOZOIDES OVINOS EM GRADIENTE DE DENSIDADE CONTÍNUO: EFEITO SOBRE A TAXA DE PRENHEZ E PROPORÇÃO DO SEXO
}

\section{CENTRIFUGATION OF OVINE SPERM IN CONTINUOUS DENSITY GRADIENT: EFFECT ON PREGNANCY RATE AND SEX RATIO}

\author{
Max Vitória Resende 1 \\ Carmo Emanuel Almeida Biscarde ${ }^{2}$ \\ Laura Emília Panelli Martins ${ }^{2}$ \\ Cláudia Kazumi Kiya² \\ Vera Fernanda Martins Hossepian de Lima $^{3}$ \\ Alberto Lopes Gusmão ${ }^{4}$ \\ ${ }^{1}$ Pós-doutor da Universidade Federal da Bahia, Salvador, BA, Brasil - maxvresende@gmail.com
2 Pós-graduandos da Universidade Federal da Bahia, Salvador, BA, Brasil
${ }^{3}$ Professora Doutora Livre Docente da Universidade Estadual Paulista, Jaboticabal, SP, Brasil
${ }^{4}$ Professor Doutor Titular da Universidade Federal da Bahia, Salvador, BA, Brasil
}

\section{Resumo:}

Este trabalho teve como objetivo avaliar a eficiência de gradientes de densidade contínuos de Percoll e OptiPrep para a separação de espermatozoides portadores do cromossomo X, e avaliar a influência sobre a viabilidade espermática, taxa de prenhez e proporção do sexo. Para isso, 100 milhões de espermatozoides foram depositados em cada tubo contendo o gradiente de densidade, previamente preparados, em tubos de poliestireno, 24 horas antes da centrifugação e mantidos a 4 ${ }^{\circ} \mathrm{C}$. Centrifugou-se a $500 \mathrm{x}$ g por 15 minutos a $22{ }^{\circ} \mathrm{C}$ e, posteriormente, os sobrenadantes foram aspirados e os espermatozoides recuperados no fundo dos tubos. Uma amostra foi avaliada antes a após a centrifugação para verificação da motilidade e vigor espermático. Os espermatozoides foram utilizados para a inseminação artificial em tempo fixo. Os resultados indicaram que a centrifugação não afetou a viabilidade espermática e a taxa de prenhez, entretanto não houve desvio da proporção do sexo para fêmeas. Mais estudos são necessários para determinar a necessidade de adaptação da técnica de centrifugação para a espécie ovina e assim obter o desvio da proporção do sexo como na espécie bovina.

Palavras-chave: carneiro; sêmen; sexagem; viabilidade espermática.

\begin{abstract}
:
The objective of this study was to evaluate the efficiency of continuous density gradients of Percoll and OptiPrep for separation of X-bearing sperm, and assess the influence on sperm viability, pregnancy rate and sex ratio. With this purpose 100 million spermatozoa were deposited into each tube containing density gradient, which were previously prepared in polystyrene tubes, 24 hours
\end{abstract}


before centrifugation and stored at $4{ }^{\circ} \mathrm{C}$. The tubes were centrifuged at 500xg for 15 minutes at 22 ${ }^{\circ} \mathrm{C}$, and then the supernatants aspirated and sperm recovered from the bottom of the tubes. A sample was evaluated before and after centrifugation to verify motility and sperm vigor. The sperm were used for fixed time artificial insemination. The results indicated that centrifugation did not affect sperm viability and pregnancy rate, however there was no deviation of sex ratio for females. More studies are needed of adapting the centrifugation technique to sheep and thus obtain the deviation of sex ration as in bovine.

Keywords: ram; semen; sexing; sperm viability.

Recebido em: 13 jun. 2013

Aceito em: 19 nov. 2014.

\section{Introdução}

Técnicas de separação de espermatozoides X e Y vêm sendo estudadas há muitos anos, devido à sua importância para a produção animal e a medicina humana, para evitar doenças ligadas ao sexo. Uma técnica que é capaz de separar espermatozoides $\mathrm{X}$ dos $\mathrm{Y}$, com acuidade de mais de $90 \%$, é a citometria de fluxo; no entanto, apesar do seu aperfeiçoamento ao longo de mais de 25 anos, ela ainda é ineficiente ${ }^{(1)}$. Além disso, ela requer a utilização de equipamento de alto custo (em torno

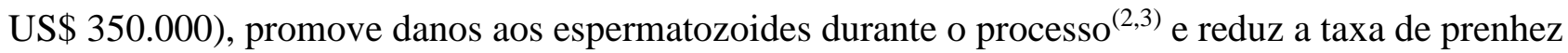
em bovinos $^{(4)}$.

Utilizando-se uma metodologia simples, a centrifugação foi capaz de separar espermatozoides bovinos $\mathrm{X}$ e Y, com menor custo, sem redução da viabilidade espermática ${ }^{(5,6)}$, sem danos ao DNA ${ }^{(7)}$ e com acuidade de $60 \%$ a $74 \%{ }^{(6,8,9)}$. Devido à importância socioeconômica da ovinocultura para $\mathrm{o}$ Brasil, onde a demanda por carne ovina vem aumentando, existe a necessidade do desenvolvimento de pesquisas para maximizar a produção nesta espécie ${ }^{(10)}$, além da possibilidade de se direcionar os nascimentos para machos ou para fêmeas, de acordo os objetivos de cada rebanho. Este trabalho teve como objetivo a separação de espermatozoides ovinos X e Y utilizando-se a centrifugação em gradiente de densidade contínua, além de avaliar a viabilidade espermática após a centrifugação e a proporção do sexo ao nascimento.

\section{Material e Métodos}

Os produtos químicos e meios utilizados foram adquiridos da Sigma (Saint Louis, USA), exceto aqueles assinalados. Os protocolos utilizados nos animais estão de acordo com os preconizados pelo Comitê de Ética no Uso de Animais (CEUA) da Escola de Medicina Veterinária e Zootecnia da UFBA e foram aprovados de acordo com o protocolo 05/2013.

Foram utilizados três carneiros da raça Dorper, com idade entre um ano e oito meses e dois anos, escore de condição 3,5 de acordo com a classificação de 1 a 5 segundo Thompson e Meyer ${ }^{(11)}$, clinicamente sadios, os quais foram submetidos previamente a exames clínicos e andrológicos, estando, portanto, aptos para reprodução, segundo preconizado pelo Manual para Exame Andrológico e Avaliação de Sêmen Animal do Colégio Brasileiro de Reprodução Animal ${ }^{(12)}$. Os 
animais foram mantidos em regime semi-intensivo de criação, pastejando em piquetes formados por capim transvala (Digitaria decumbens) e receberam concentrado balanceado, sal mineral e água ad libitum. Para o experimento, utilizaram-se somente ejaculados que continham no mínimo $70 \%$ de motilidade progressiva, vigor 4 e concentração espermática total de $2 \times 10^{9}$ espermatozoides $/ \mathrm{mL}$.

Para a colheita do sêmen, realizou-se previamente a higienização do prepúcio de cada animal e foi empregado o método da vagina artificial contendo água pré-aquecida com temperatura entre $40 \mathrm{e}$ $45^{\circ} \mathrm{C}$, utilizando-se uma ovelha em estro natural ou induzido, como manequim. As colheitas foram realizadas duas vezes por semana, seis colheitas de sêmen por animal, totalizando 18 ejaculados. As médias obtidas para motilidade, vigor e concentração espermática do sêmen recém-colhido foram de $84,04 \%, 4,85$ e $3 \times 10^{9} / \mathrm{mL}$, respectivamente.

O gradiente de Percoll (Pharmacia Fine Chemicals, Uppsala, Sweden) foi elaborado misturando-se a solução estoque de Percoll com DMEM, pH 7.4, 280 a $290 \mathrm{mOsm} / \mathrm{Kg}_{\mathrm{H}} / \mathrm{H}_{2} 0$, com 0,3\% (peso/volume) de BSA (Calbiochem, Darmstadt, Germany), para se obterem densidades variando de 1.110 a $1.123 \mathrm{~g} / \mathrm{mL}$. O gradiente de OptiPrep foi preparado misturando-se diferentes proporções de DMEM contendo 0,3\% (peso/volume) de BSA (Calbiochem, Darmstadt, Germany), pH 7,4 para se obterem densidades variando de 1,110 a $1,123 \mathrm{~g} / \mathrm{mL}$. As três camadas dos gradientes de densidade contínuos de Percoll e OptiPrep foram consecutivamente montadas em tubos de $15 \mathrm{~mL}$ de poliestireno. Os tubos permaneceram a $4{ }^{\circ} \mathrm{C}$ por $24 \mathrm{~h}$ para transformação do gradiente descontínuo em um gradiente contínuo de densidade, coforme descrito no Manual de Elaboração de Gradiente de Densidade ${ }^{(13)}$.

Para a centrifugação, cerca de 100 milhões de espermatozoides recém-colhidos (sêmen fresco) foram depositados sobre cada tubo contendo os gradientes contínuos de Percoll e OptiPrep. A motilidade foi avaliada subjetivamente, utilizando-se microscópio de luz com contraste de fase, e a concentração espermática por meio da câmera de Neubauer. Os tubos foram centrifugados a 500 x $g$ por 15 min a $22{ }^{\circ} \mathrm{C}$. Os sobrenadantes foram cuidadosamente aspirados e os espermatozoides, localizados no fundo dos tubos, colhidos. A concentração espermática, motilidade e a taxa de recuperação foram determinadas. Os espermatozoides foram utilizados para o controle de qualidade da centrifugação pela coloração de Azul de Tripan / Giemsa (avaliação da integridade de membrana e do acrossoma) e para a inseminação artificial. Uma alíquota não foi centrifugada (grupo controle) com intuito de se efetuar a comparação com os grupos Percoll e OptiPrep.

A membrana espermática e a integridade do acrossoma foram avaliadas por microscopia de luz comum de acordo com Didion et al. ${ }^{(14)}$, com pequena modificação, pelo uso da coloração Azul de Tripan / Giemsa. Uma amostra de $20 \mu \mathrm{L}$ de cada tratamento (Percoll e OptiPrep) e do grupo Controle (não centrifugado) foram incubadas com $20 \mu \mathrm{L}$ de do corante Azul de Tripan 0,4\% a 37 ${ }^{\circ} \mathrm{C}$ por $20 \mathrm{~min}$, quando então foram centrifugadas duas vezes a $700 \mathrm{x} g$ por $5 \mathrm{~min}$. $\mathrm{O}$ sedimento foi re-suspenso com $0,5 \mathrm{~mL}$ de água destilada, dois esfregaços de cada amostra foram confeccionados, fixados em metanol por for 5 minutos, secos e corados por 18 a 20 h com Giemsa (10\%). As lâminas foram avaliadas contando-se 200 espermatozoides em microscópio de luz comum, com aumento de 400X, sendo os espermatozoides classificados em vivos com acrossoma intacto (VI), vivo sem acrossoma (VSA) e mortos.

Cento e trinta e cinco ovelhas mestiças de Dorper e Santa Inês, divididas aleatoriamente, em três grupos (Percoll, OptiPrep e Controle), foram submetidas a um protocolo de sincronização, no qual no Dia 0 foi inserido dispositivo intravaginal de progesterona (Progespon ${ }^{\circledR}$, MSD Saúde Animal, Brasil), no Dia 6 foram aplicados 400UI de eCG (Novormon $^{\circledR}$, MSD Saúde Animal, Brasil) e 
37,5 $\mu$ g de prostaglandina $\left(\operatorname{Ciosin}^{\circledR}\right.$, MSD Saúde Animal, Brasil) e retirado o dispositivo de progesterona.

As fêmeas foram inseminadas por via laparoscópica, 55 horas após a retirada do dispositivo intravaginal contendo progesterona, no D9. O meio contendo espermatozoides centrifugados nos gradientes de densidade foi envasado em palhetas de sêmen de 0,25 mL (IMV Technologies, Paris, França) com concentração de 15 a 20 × $10^{6}$ espermatozoides por dose. As palhetas foram colocadas em bainhas para inseminação (Aspic®, IMV Technologies, Paris, França). As fêmeas foram previamente tratadas com anestesia dissociativa composta de $4 \%$ de cloridrato de xilazina (Dorcipec®, Vallée, Brasil), 20\% de cloridrato de ketamina (Vetenarcol®, König, Argentina) e $76 \%$ de solução salina, na dosagem de $1 \mathrm{~mL} / 10 \mathrm{~kg}$ de peso vivo e, posteriormente, após a tricotomia, receberam $2 \mathrm{~mL}$ de cloridrato de lidocaína a 2\% (Anestésico Bravet ${ }^{\circ}$, Bravet, Brasil) no local da introdução dos trocateres. Preventivamente, cada animal recebeu $10 \mathrm{mg} / \mathrm{kg}$ de peso vivo de oxitetraciclina LA (Terramicina LA®, Pfizer, Brasil) pela via intramuscular. Após as inseminações, os animais tiveram as feridas cirúrgicas tratadas com "spray" cicatrizante (Bactrovet Prata AM®, König, Brasil) e repelente contra insetos (Valléecid Spray® Vallée, Brasil), mantendo-se o tratamento até completa cicatrização.

O diagnóstico de gestação foi realizado 35 dias após a inseminação artificial, por ultrassonografia via transretal com probe de $5 \mathrm{MHz}$, adaptada para pequenos ruminantes, utilizando-se um suporte rígido. A proporção do sexo foi avaliada ao nascimento, com observação direta da genitália das crias.

Os dados obtidos dos espermatozoides corados com Azul de Tripan/Giemsa foram avaliados utilizando-se o Teste exato de Fisher. A taxa de prenhez e a proporção do sexo foram avaliadas pelo Teste do Qui-quadrado. Algumas fêmeas pariram mais de um produto, sendo o sexo de ambos considerado na análise estatística da proporção do sexo. Para todas as análises foi considerada significativa uma probabilidade de $5 \%$.

\section{Resultados e Discussão}

Neste trabalho, pela primeira vez em nosso conhecimento, foi utilizada a centrifugação em gradientes de densidade contínuos de Percoll e OptiPrep na tentativa de se separarem espermatozoides $\mathrm{X}$ ovinos recém colhidos e utilizá-los diretamente para inseminação artificial. Além disso, foi verificada a viabilidade espermática e integridade do acrossoma por meio de teste in vitro.

Antes da centrifugação, a média de motilidade foi de 84,04\% e após a centrifugação, 63,63\% e 70,76\% para o grupo Percoll e OptiPrep, respectivamente. A taxa de espermatozoides recuperados no sedimento, após a centrifugação, foi de 22,12\% e 20,05\% para o Percoll e OptiPrep, respectivamente, o que foi semelhante aos resultados obtidos por Hossepian de Lima et al. ${ }^{(9)}$, utilizando sêmen bovino congelado e centrifugado em gradiente descontínuo de Percoll. Com a utilização de sêmen bovino congelado e aplicando também gradientes contínuos, Resende et al. ${ }^{(8)}$ obtiveram taxas de recuperação média de 5,7\% e 19,4\%, para Percoll e OptiPrep, respectivamente, sendo que somente o grupo Percoll obteve sucesso na separação de espermatozoides X.

Mousset-Simeon et al. ${ }^{(15)}$ demonstraram que o OptiPrep foi menos efetivo do que o Percoll em separar espermatozoides humanos com motilidade e sem alteração na morfologia. Contrariamente, 
os resultados obtidos aqui indicaram que o Percoll e o OptiPrep foram semelhantes quanto à motilidade pós-centrifugação, o que está de acordo com os resultados encontrados em trabalho com humanos $^{(16)}$ e bovinos ${ }^{(5)}$.

Os resultados da viabilidade espermática e integridade do acrossoma pela coloração Azul de Tripan/Giemsa estão apresentados na Tabela 1, com a comparação das classes de espermatozoides (VI, VSA e mortos) antes (grupo controle) e após a centrifugação nos gradientes de Percoll e OptiPrep (grupos sexagem). O grupo Percoll apresentou a menor porcentagem de espermatozoides VI (73\%); contudo, não deferiu em relação ao grupo OptiPrep e ao grupo não centrifugado $(\mathrm{P}>0,05)$. A classe VI representa espermatozoides íntegros, no aspecto da viabilidade e integridade do acrossoma, porém espermatozoides VSA são capazes de fecundar, desde que o tempo requerido entre centrifugação e a fecundação não seja longo, o que seria somente utilizado em processo in vitro $^{(17)}$.

Tabela 1: Porcentagens de espermatozoides após a coloração com Azul de Tripan/Giemsa dos grupos sexagem (Percoll e OptiPrep) e grupo não centrifugado (Controle) de acordo com as classes de espermatozoides

\begin{tabular}{ccccc}
\hline \multirow{2}{*}{ Grupo } & No. de espermatozoides & \multicolumn{3}{c}{ Classes de espermatozoides (\%) } \\
\cline { 2 - 5 } contados & 200 & $73,0^{\mathrm{a}}$ & $17,0^{\mathrm{a}}$ & Mortos \\
\hline Percoll & 200 & $78,0^{\mathrm{a}}$ & $7,0^{\mathrm{b}}$ & $10,0^{\mathrm{b}}$ \\
OptiPrep & 200 & $77,0^{\mathrm{a}}$ & $5,0^{\mathrm{b} c}$ & $18,0^{\mathrm{ab}}$ \\
Controle (não & & & \\
centrifugado) & & &
\end{tabular}

VI: vivos com acrossoma intacto, VSA: vivo sem acrossoma e mortos. Valores seguidos de letras diferentes nas colunas diferem entre si $(\mathrm{P}<0,05)$.

Utilizando técnica semelhante de separação de espermatozoides, Resende et al. ${ }^{(5)}$ verificaram que o processo de centrifugação selecionou uma maior porcentagem de espermatozoides bovinos vivos com acrossoma intacto, em média, 21\%. No presente trabalho, os resultados foram superiores, obtendo no mínimo $73 \%$ de espermatozoides vivos com acrossoma intacto, apesar da diminuição no grupo Percoll em relação ao grupo não centrifugado. Este fato pode ser explicado pela utilização, neste trabalho, de espermatozoides recém-colhidos e não criopreservados, ao contrário do que foi utilizado em outros trabalhos com o mesmo objetivo, ou seja, a separação de espermatozoides $X^{(5,6)}$. O fato de a criopreservação provocar danos à membrana e a perda do acrossoma já foi anteriormente descrito ${ }^{(18)}$.

Os dados obtidos de taxa de prenhez após a inseminação artificial de ovelhas com espermatozoides centrifugados estão contidos na Tabela 2. A taxa de prenhez não diferiu entre os grupos centrifugados em gradiente de Percoll e OptiPrep $(\mathrm{P}>0,05)$ do grupo controle, em que os espermatozoides não foram submetidos à centrifugação. Como pode ser observado, o processo de centrifugação em gradientes de densidade não compromete, significativamente, a taxa de prenhez. Estes resultados são importantes no intuito de, no futuro, realizarem-se adaptações na técnica de centrifugação para a espécie ovina e, possivelmente, utilizá-la na espécie caprina, na tentativa de desvio da proporção do sexo para fêmeas. 
Tabela 2: Taxa de prenhez após inseminação artificial de ovelhas com espermatozoides centrifugados em gradiente de densidade contínuo de Percoll e OptiPrep e grupo controle (não centrifugado)

\begin{tabular}{cccc}
\hline Grupos & $\begin{array}{c}\text { Fêmeas } \\
\text { inseminadas }\end{array}$ & $\begin{array}{c}\text { Taxa de prenhez } \\
\mathbf{n}(\%)\end{array}$ & Valor de P \\
\hline Percoll & 48 & $27(56,25 \%)$ & 0,11 \\
OptiPrep & 45 & $30(66,67 \%)$ & 0,56 \\
Controle & 40 & $29(72,50 \%)$ & - \\
\hline
\end{tabular}

Nåo houve diferença estatística entre os grupos $(\mathrm{P}>0,05)$.

Apesar de não ter ocorrido diminuição significativa, na taxa de prenhez, não foi observado desvio da proporção do sexo para fêmeas $(\mathrm{P}>0,05)$, que constituía o objetivo da centrifugação dos espermatozoides nos gradientes de densidade contínuos de Percoll e OptiPrep (Tabela 3).

Tabela 3: Proporção do sexo ao nascimento em ovelhas inseminadas com espermatozoides centrifugados em gradiente de densidade contínua de Percoll e OptiPrep comparados ao grupo controle (não centrifugado)

\begin{tabular}{cccc}
\hline & \multicolumn{3}{c}{ Proporção do sexo } \\
\cline { 2 - 4 } Grupos & $\begin{array}{c}\text { Macho } \\
\text { n (\%) }\end{array}$ & $\begin{array}{c}\text { Fêmea } \\
\text { n (\%) }\end{array}$ & Valor de P \\
& $13(48,15 \%)$ & $15(53,57 \%)$ & 0,69 \\
Percoll & $14(46,67 \%)$ & $17(54,84 \%)$ & 0,61 \\
OptiPrep & $16(51,61 \%)$ & $15(48,39 \%)$ & - \\
Controle & &
\end{tabular}

Nåo houve diferença estatistica entre os grupos $(\mathrm{P}>0,05)$.

Estes resultados ficaram abaixo dos obtidos em outros trabalhos que utilizaram sêmen criopreservado e que apreentaram desvio para o sexo feminino em torno de $62 \%$, quando se utilizou gradiente contínuo $^{(8)}$, e de $55,7 \%^{(19)}, 62 \%^{(6)}$ e $75 \%^{(9)}$, quando utilizaram-se gradientes descontínuos. Observa-se que, mesmo para bovinos, a técnica de centrifugação precisa ser aprimorada, no intuito de melhorar a sua repetitividade. Este fato pode ser devido à montagem dos gradientes de densidade ser feita de forma manual, enquanto que na citometria de fluxo, que apresenta resultados mais homogêneos, o processo de separação dos espermatozoides $\mathrm{X}$ dos $\mathrm{Y}$ é realizado em equipamento computadorizado que analisa os mesmos um a um ${ }^{(2)}$.

\section{Conclusões}

Concluiu-se que o processo de centrifugação em gradientes de densidade contínuos de Percoll e OptiPrep, na espécie ovina, não interferiu na taxa de prenhez e na viabilidade espermática. No entanto, não foi possível verificar o desvio da proporção do sexo para fêmeas. Existe a necessidade de se desenvolverem mais estudos para adaptar a técnica de centrifugação para a espécie ovina e 
assim se obter o desvio da proporção do sexo para fêmeas, já que, originalmente, a técnica foi desenvolvida para bovinos.

\section{Agradecimentos}

Este trabalho foi financiado pela CAPES, projeto PNPD, processo: $23038.007863 / 2008-47$.

\section{Referências}

1. Burroughs CA, Grahama JK, Lenz RW, Seidel Jr GE. Seminal plasma effects on sex-sorting bovine sperm. Theriogenology. 2013;79:551-557.

2. Seidel Jr. GE. Overview of sexing sperm. Theriogenology. 2007;68:443-446.

3. Carvalho, JO, Sartori R, Machado G, Mourão GB, Dode MAN. Quality assessment of bovine cryopreserved sperm after sexing by flow cytometry and their use in in vitro embryo production. Theriogenology. 2010;74:1521-1530.

4. Dominguez JHE, Costa DS, Centurion VJ, Faria FJC. Pregnancy rate of Nelore females inseminated with male-sexed semen. Anim Reprod Sci 2011;129:127-131.

5. Resende MV, Bezerra MB, Perecin F, Almeida AO, Lucio AC, Hossepian de Lima VFM. Separation of $\mathrm{x}$-bearing bovine sperm by centrifugation in continuous Percoll and Optiprep density gradient: effect in sperm viability and in vitro embryo production. Cienc. Anim. Bras. 2009;10:581587.

6. Lucio AC, Resende MV, Dernowseck-Meirelles JA, Perini AP, Oliveira LZ, Miguel MCV, Carmo AS, Tomita SY, Alves BCA, Fazano FAT, Hossepian de Lima VFM. Assessment of swimup and discontinuous density gradient in sperm sex preselection for bovine embryo production. Arq. Bras. Med. Vet. Zootec. 2012;64:525-532.

7. Resende MV, Lucio AC, Perini AP, Oliveira LZ, Almeida AO, Gusmão AL, Hossepian de Lima VFM. Desvio da proporção de sexo e integridade do DNA dos espermatozoides bovinos centrifugados em gradientes de densidade contínuos. Rev. Bras. Saude Prod. Anim. 2010;11:260269.

8. Resende MV, Lucio, AC, Perini AP, Oliveira LZ, Almeida AO, Alves, BCA, Moreira-Filho CA, Santos IW, Hossepian de Lima VFM. Comparative validation using quantitative real-time PCR (qPCR) and conventional PCR of bovine semen centrifuged in continuous density gradient. Arq. Bras. Med. Vet. Zootec. 2011;63:544-551.

9. Hossepian de Lima VFM, Moreira-Filho CA, Lucio AC, Resende MV. Sexagem de espermatozoides bovinos por centrifugação em gradiente descontínuo de densidade de Percoll. Rev. Bras. Zootec. 2011;40:1680-1685.

10. Viana JGA, Silveira VCP. Análise econômica da ovinocultura: estudo de caso na Metade Sul do Rio Grande do Sul, Brasil. Cienc. Rural. 2009;39:1187-1192. 
11. Thompson J, Meyer H. Body condition scoring sheep. Oregon: Oregon State University, 1994, 4p. Disponível em http://ir.library.oregonstate.edu/xmlui/bitstream/handle/1957/14303/ec1433.pdf, acesso em 22 janeiro de 2015.

12. CBRA (COLÉGIO BRASILEIRO REPRODUÇÃO ANIMAL). Manual para exame andrológico e avaliação de sêmen animal. $3^{\mathrm{a}}$ ed. Belo Horizonte: CBRA, 2013. 104p. Portuguese.

13. Density Gradient Media. Application Sheet C02. 6 ed. Norway:Axis-Shield, 2011. 6p. Disponível em http://www.axis-shield-density-gradient-media.com/New\%20catalog\%2020121.pdf, acesso em 22 janeiro de 2015.

14. Didion BA, Dobrinsky JR, Giles JR, Graves CN. Staining procedure to detect viability and the true acrosome reaction in spermatozoa of various species. Gamete Res. 1989;22:51-57.

15. Mousset-Siméon N, Rives N, Masse L, Chevallier F, Mace B. Comparison of six density gradient media for selection of cryopreserved donor spermatozoa. J Androl. 2004;25:1-4.

16. Claassens OE, Menkveld R, Harrison KL. Evaluation of three substitutes for Percoll in sperm isolation by density gradient centrifugation. Hum Reprod. 1998;13:3139-3143.

17. Johnson LA. Sexing mammalian sperm for production of offspring: the state-of-the-art. Anim Reprod Sci. 2000;60:93-107.

18. Watson, PF. The causes of reduced fertility with cryopreserved semen. Anim Reprod Sci. 2000;60-61:481-492.

19. Kobayashi J, Oguro H, Uchida H, Kohsaka T, Sasada H, Sato E. Assessment of bovine X- and Y-bearing spermatozoa in fractions by discontinuous Percoll gradients with rapid fluorescence in situ hybridization. J Reprod Dev. 2004;50:463-469. 